\title{
Ética da AMIZADE E DeficiênCIA: OUTRAs Formas de CONVÍVIO COM O DEVIR DEFICIENTE NA ESCOLA
}

\author{
Pedro Angelo Pagni ${ }^{1}$ \\ Universidade Estadual Paulista Júlio de Mesquita Filho - UNESP
}

\begin{abstract}
Resumo
\end{abstract}
Após a implantação das políticas de inclusão, no Brasil, tem sido cada vez mais frequente a ocorrência de relações de amizades entre os atores da escola denominados "deficientes" com os demais. Muitas vezes, tais relações ultrapassam o tempo e o espaço, os saberes e o currículo escolar, produzindo modos de existência comuns e uma ética transversal, raramente vistos pela instituição. Essa invisibilidade é acentuada ainda mais no cenário biopolítico atual, que corrobora certa desconfiança referente aos modos de existência deficientes e ao devir comum que produzem nas relações amistosas entretecidas pelos atores da escola. Nessa conjuntura, este ensaio analisa a ética da amizade com os deficientes e a confiança como uma das condições de sua consecução na escola. A partir da estética da existência de Michel Foucault, objetivamos discutir: (1) se a amizade com a deficiência pode se apresentar como uma nova ética, capaz de interpelar os dispositivos formais e de resistir às tecnologias de biopoder da escola, quem sabe, criando outras formas de inclusão; (2) se a confiança no devir comum produzido nessas particulares relações amistosas pode ser considerada uma das condições de sua consecução e como uma estratégia para reverter a atual desconfiança no deficiente, em vistas a minimizar o temor e a visibilizar o signo do acontecimento da vida que representa. Com a discussão dessas questões, esperamos contribuir para que a amizade com a deficiência seja vista como signo de uma formação dos atores da escola e a confiança no devir deficiente se torne visível como uma luta transversal comum que, além de condição para a consecução da ética da amizade, se apresente como uma estratégia política importante para potencializar essas vidas distintas que merecem ser vividas.

Palavras-chave: ética da amizade; deficiência; confiança; escola.

\section{ETHICS OF FRIENDSHIP AND DISABILITY: OTHER FORMS OF CONVIVIALITY WITH THE BECOMING OF THE DISABLED STUDENT AT SCHOOL}

\begin{abstract}
After the implementation of inclusion policies in Brazil, friendship relations between the actors of the school so called "disabled" students and the rest of students have become increasingly frequent. Often these relationships go beyond time and space, the knowledge and the curriculum, to produce common modes of existence and a transverse ethics rarely seen by the institution. This invisibility is even more accentuated in the case of nowadays biopolitics scenario, which corroborates to raise suspicion concerning the disabled modes of existence and the joined becoming produced by the friendly relations between the actors at school. Given the context, this essay examines the ethics of friendship regarding the disabled ones and the trust as one of the conditions of its achievement at school. Drawing from the aesthetics of existence of Michel Foucault, my goal is to discuss: (1) whether friendship with the disabled one may present itself as a new ethic that is able to question current formal apparatus and resist the biopower technologies in school, perhaps
\end{abstract}

\footnotetext{
${ }^{1}$ E-mail: pagni@terra.com.br
} 
creating other forms of inclusion; (2) whether the trust in the joined becoming that emerges from such friendly relations can be regarded as one of the conditions for their achievement and a strategy to reverse the current mistrust in the disabled one, in order to minimize fear and bring into existence a sign of the life event that it represents. By addressing these issues, I hope to contribute in a way in which the friendship with disabled ones is seen as a sign of a formation of the actors at school and the trust in the becoming disabled becomes visible as a transverse common struggle: the condition for the achievement of the ethics of friendship that introduces itself as a major political strategy to leverage these separate lives that deserve to be lived.

Keywords: ethics of friendship; disabilities; trust; school.

\section{ÉTICA DE LA AMISTAD Y LA DISCAPACIDAD: OTRAS FORMAS DE CONVIVENCIA CON EL DEVENIR DEFICIENTE EN LA ESCUELA}

\section{Resumen}

Después de la implementación de políticas de inclusión en Brasil, ha sido cada vez más frecuente darnos cuenta de las relaciones de amistad entre los llamados "discapacitados" con los demás actores de la escuela. A menudo, tales relaciones van más allá del tiempo y el espacio, el conocimiento y el currículo escolar, produciendo modos de existencia comunes y una ética transversal, pocas veces vistos por la institución. Esta invisibilidad se acentúa todavía más sobre en la actual configuración biopolítica y corrobora algunas sospechas con respecto a los modos de existencia deficientes y al devenir común que producen en las relaciones de amistad entretejidas por los actores de la escuela. En este contexto, este ensayo examina la ética de la amistad en personas con discapacidad y la confianza como una de las condiciones de su logro en la escuela. Desde la estética de la existencia de Michel Foucault, pretendemos discutir: (1) si la amistad con la deficiencia puede presentarse como una nueva ética, capaz de hacer dispositivos formales y resistir a las tecnologías de biopoder en la escuela, tal vez creando otras formas de inclusión; (2) si la confianza en el devenir común producido por estas particulares relaciones amistosas puede considerarse como una de las condiciones de su logro y como una estrategia para revertir la actual desconfianza en las personas con discapacidad, con el fin de minimizar el temor y visualizar el signo del acontecimiento de la vida que ellas representan. Con la discusión de estos temas, esperamos contribuir para que la amistad con la discapacidad sea mirada como signo de una formación de los actores de la escuela y la confianza en el devenir deficiente se haga visible como una lucha común transversal, que además de condición para el logro de la ética de la amistad, se presenta como una importante estrategia política para potencializar esas vidas distintas que merecen ser vividas.

Palabras clave: ética de la amistad; discapacidad; confianza; escuela. 


\section{Ética da Amizade e DeficiênCIA: OUtRas Formas de Convívio Com o Devir DEFICIENTE NA ESCOLA}

Ao final de sua vida, Michel Foucault compreendeu a amizade homoerótica como signo de um novo código de comunicação entre duas pessoas. As alianças entretecidas nessa relação, diz Foucault (1981, p. 38), "traçam linhas de forças imprevistas", assumem um caráter perturbador, pois, "o modo de vida homossexual muito mais que o ato sexual mesmo", implica num ethos, que pode sacudir as instituições. Nesse sentido, considerou que se os "códigos institucionais não podem validar estas relações das intensidades múltiplas, (...), das formas que se modificam", essas "relações instauram um curto-circuito e introduzem o amor onde deveria haver a lei, a regra ou o hábito" (FOUCAULT, 1981, p. 38, grifos meus).

O curto-circuito a que o filósofo francês se refere nesta passagem ocorre em virtude da exigência de uma nova ascese. Na relação de amizade, essa ascese levaria cada um dos envolvidos a inventar "uma maneira de ser, ainda improvável" que, antes do que lhes mobilizar para que investissem na "liberação de desejos", apelaria para que se tornassem "infinitamente mais suscetíveis a prazeres" (FOUCAULT, 1981, p. 39). Diante do empobrecimento das relações interpessoais e da miséria amorosa contemporâneos, essa amizade seria tomada como campo de experimentação para a criação de outro tipo de interpelações subjetivas e como indicativo de emergência de uma nova ética. Nas linhas diagonais do tecido social, o testemunho da amizade proveniente da militância homossexual desse intelectual francês contribuiu para chamar a atenção para aquele empobrecimento relacional, indicando não apenas o esfacelamento da teia afetiva na qual se sustenta, como também a possibilidade de um determinado tipo de relação, uma ascese e uma ética próprias como aquela propiciada pela cultura homossexual e pela amizade que aspira e inspira. Michel Foucault deu visibilidade, dessa forma, a uma luta transversa aos processos de individualização estatal e de homogeneização da população, encontrando nessa nova ética um sentido político de resistência no campo em que atua e de militância nas lutas 
locais com as quais se defrontou ${ }^{2}$. Contudo, salvo por duas entrevistas ${ }^{3}$, a sua morte o impediu que esse projeto fosse levado adiante e deixou aberta toda uma discussão sobre as relações entre estética e política que compreendem essa temática - posteriormente explorada no debate filosófico por seus contemporâneos ${ }^{4}$.

É essa abertura propiciada pelo percurso do último Foucault e a tese defendida por Francisco Ortega (1999) - de que a incursão na temática da amizade foi para ele um modo de atualizar a estética da existência - que gostaria de assumir neste ensaio como pontos de partida para discutir se as relações interpessoais com o/as denominado/as deficientes, emergentes em instituições como as escolas, após a implantação de políticas de inclusão, poderiam ser considerados como formas de produção de uma nova ascese ou de criação de um ethos próprio. Interessa-me desse ponto de vista indagar se as relações dos atores da escola com os denominados deficientes teriam sido capazes de fazer emergir transversalmente ao espaço, ao tempo e ao currículo, uma particular ética da amizade, marcada por algumas características próprias, mas que possui potencial análogo para recriar modos de vida outros, distintos daqueles pensados por Foucault em sua militância. No marco de um programa de pesquisa ${ }^{5}$ mais amplo, este ensaio se

\footnotetext{
${ }^{2}$ Interessou mais a Foucault ao que tudo indica, porém, ao invés de exaltar esta militância, investigar na Antiguidade Grega e Romana algumas das configurações da ética da amizade com a provável expectativa de contrastá-la com o atual esvaziamento das relações interpessoais nas instituições sociais. Ao menos foi o que demonstrou em sua análise dos epicuristas e do estoicismo no curso Hermenêutica do sujeito e dos cínicos no curso Coragem de Verdade, nos termos em que procurei interpretar em outra ocasião (PAGNI, 2014b).

${ }^{3}$ As duas entrevistas a que me refiro aqui são as seguintes. A primeira foi concedida por Michel Foucault a R. de Ceccaty, J. Danet e J. le Bitoux, publicada no jornal Gai Pied, em abril de 1981, intitulada L'amitié comme mode de vie. A segunda foi concedida a G. Barbedette, publicada em 1982, com o título Triunfo social do prazer sexual: uma conversação com Michel Foucault. Em rápidas palavras, nesta última entrevista, Foucault (2004b) parte do diagnóstico do empobrecimento do mundo relacional pelas instituições e da busca no espaço vazio aí deixados da "possibilidade de criar novas possibilidades de relação", encontrando na experiência homossexual uma forma de escapar a normalização da sexualidade. Por sua vez, na primeira entrevista, Foucault (1981) nomeia essas possibilidades de relação de amizade. E, no caso deste indicativo, embora declare sua paixão pelos gregos e aí adote a estratégia de contrastar o amor homoerótico na Antiguidade com as atuais relações homoafetivas, a amizade então denominada assume um caráter central na constituição de uma nova ascese.

${ }^{4}$ Precisamente, tal discussão o insere em uma tradição mais ampla na qual as relações entre estética e política já vinham sendo objeto de reflexão, como no caso de algumas obras de Hanna Arendt (2010) e de Jürgen Habermas (1990), assumindo nesse debate uma posição singular, assim como, em solo francês, essa discussão pode ser verificada nas obras de Jacques Rancière (1996), Jean François Lyotard (1993), dentre outros.

${ }^{5}$ Esse programa se intitula Biopolítica, ética da diferença e educação: outro olhar sobre a inclusão retratos da positividade da deficiência e é desenvolvido com o apoio da FAPESP e do CNPq,
} 
propõe a discutir duas questões. A primeira delas se refere à questão se, em torno dessa ética da amizade e de sua consecução, não se poderia encontrar um solo mais fecundo para falar de uma inclusão que ultrapasse os registros exclusivamente jurídico ou político-estatal sobre os quais vem se atendo em países como o Brasil, assim como as suas bases de legitimação científica e tecnológicas. Caso haja uma resposta afirmativa a essa questão e a confiança possa ser considerada uma condição da ética referida, a segunda questão se refere ao como confiar no/a deficiente e no devir comum decorrente de sua amizade com os demais sujeitos num mundo em que a desconfiança e o ódio do que representam se faz presente. Dessa forma, analiso e discuto o sentido ético e o significado político da confiança como condição e como meio para emergência de uma ética da amizade com os deficientes na escola, em vistas a ampliar o campo de visibilidade sobre essa forma de luta transversa e os efeitos dos modos de vida provocados por seu devir comum.

\section{Da inclusão jurídica-politica a uma ética da amizade com a deficiência na escola}

Na amizade há uma conversa feita com palavras e sem palavras: a manifestação extrema do estar, que não admite cognição nem superposição nem autoridade. (SKLIAR, 2014, p. 49)

Desde a última década no Brasil, uma série de ações inclusivas decorreram de políticas estatais, sendo bastante comum que a população as percebesse mais como uma benfeitoria do Estado do que um legítimo direito da sociedade civil e das comunidades que lutaram para serem reconhecidas por sua diversidade étnico-racial ou cultural, por sua diferença de gênero ou de orientação sexual ou por sua deficiência. Aliás, essa forma de governamentalidade estatal continuou a ser mesclada com uma série de valores morais relativos à piedade de alguns desses segmentos da população (creditando a eles certa minoridade ou incapacidade) ou a aspirar princípios jurídicos referentes a uma igualdade formal que, ao mesmo tempo em que concede direitos a esses mesmos segmentos -por vezes, sem ouvi-los ou, mesmo, arrogando-se a um gesto de suposta superioridade - , interdita a sua efetiva participação na esfera pública e os 
estigmatiza mesmo sob o signo de sua inclusão. Em outras palavras, é como se os segmentos dessa população fossem permitidos participar do jogo, mas como jogadores cujas aptidões e lances são vistos, respectivamente, com desconfiança e, em função disso, com uma expectativa muito abaixo do esperado pelos demais. Sequer se cogita no âmbito dessas políticas ditas afirmativas a possibilidade de que uma atitude e uma estilística novas possam se exprimir em suas práticas e emergir em sua ação, colocando em xeque as regras, a plástica e a arte próprias desse jogo. Tais políticas inclusivas, assim, têm garantido direitos aos segmentos da população denominados de minoritários para que, uma vez acomodados no jogo, o seu efetivo protagonismo das lutas na atual configuração biopolítica seja obscurecido em função desse risco que representam e, consequentemente, secundarizados por um conjunto de práticas legitimadas em saberes e empreendida por tecnologias produzidas por um corpo de profissionais especializados. Por sua vez, esse corpo de profissionais especializados parece se ocupar em produzir conhecimentos capazes de diagnosticar os segmentos da população identificados com as diversidades culturais, diferenças e deficiências que indicam certo risco, tratando de alguns desses casos ou, mesmo, evitando-os preventivamente por meio de tecnologias que atuam individualmente sobre seus corpos. Esses procedimentos, em tese, tornariam tais segmentos da população capazes de responder aos atuais padrões de eficiência e de normalidades, que agrupam os indivíduos segundo critérios identitários diversos, e não mais unos, porém, aglutinados em torno das demandas do mercado de consumo e de produção - nessa ordem.

Os saberes e tecnologias produzidas em programas de inclusão escolar parecem responder a esse esquema geral e a normas específicas relativas à cada deficiência, pautado numa inclusão que adapta o organismo vivo a certas destinações relacionadas à sua ocupação funcional no mercado de consumo ou de trabalho previamente estabelecida. Pode-se dizer que dessa forma os seus modos de existir no mundo, assim como a sua expressividade, dificilmente são considerados racionalmente e vistos pelos demais. 
Advindo de saberes articulados em torno de uma epistême, os deficientes são apenas objetos de estudo sobre o qual se fala a respeito, se classifica a partir de um diagnóstico e se prognostica uma espécie de tratamento especial. O que parece raro nesse processo para aqueles saberes, para as tecnologias que legitima e para as práticas que produzem é se dar conta da subjetividade desses sujeitos denominados deficientes, suas experiências e suas falas quando possíveis - ou, quando não, os relatos daqueles que lhes são próximos, tais como pais, familiares, amigos ou cuidadores, decorrentes de uma experiência com eles. Isso ocorre porque tais relatos e experiências são, em geral, colocados em xeque por um objetivismo, por uma estéril necessidade estatística para definir o que é médio - e, portanto, normal - e por uma racionalidade econômica similar à denunciada por Foucault (2008) ao analisar a biopolítica neoliberal.

Em razão desse suposto objetivismo, uma série de tecnologias são testadas e validadas para otimizar o funcionamento dos corpos desses sujeitos, tratados como objetos, e adaptá-los a uma certa funcionalidade esperada socialmente, naturalizada como um fim indiscutível, para que certa concepção formal de inclusão ocorra. Nesse sentido, os efeitos dessa inclusão formal, por assim dizer, podem corresponder aos esperados pelas políticas públicas. Ademais, eles facultam uma concorrência entre os especialistas para saber qual modelo de acessibilidade do espaço físico, qual programa de adaptação de conteúdos curriculares, qual métodos de ensino, estratégias didáticas de disciplinamento e de avaliação são as mais adequadas para essas políticas estatais, que no fundo são capitaneadas pela livre iniciativa privada. Dessa perspectiva hegemônica, o que escapa ao formalmente instituído pela lei, pelos saberes especializados e pelas tecnologias oficializadas ou reconhecidas como as melhores, para essa adaptação funcional desses indivíduos e o para o controle biopolítico de suas vidas designadas de deficientes, raramente são levadas em conta.

É o que se observa na escassa literatura a esse respeito. Não fosse estudos como os protagonizados por Carlos Skliar (2003), desenvolvidos mais recentemente por Ignácio Calderón Almendros (2014) e analisados por Ana 
Cristina Boherer Gilbert (2012), dentre outros, foco algum se teria em tal questão. Ainda que, como afirma Gilbert (2012), os relatos do/as deficientes ou de seus pais e familiares se enquadrem muitas vezes a uma espécie de ajustamento ao lema de que o diferente é normal - acompanhado pela mídia e pelos blogs, dentre outros meios de comunicação - e à biopolítica neoliberal, mesmo assim, pouco seriam ouvidos pelos diretores, especialistas e professores na escola. Na realidade, dificilmente essas vozes ou os signos de sua expressão são escutados e percebidos como parte de uma rede mais densa e complexa que se forma a partir dessa pequena comunidade de elementos, de coadjuvantes e de jogadores ignorados, não obstante possam aspirar ser também atores, protagonistas e terem vistos seus lances.

Nesse jogo cuja invisibilidade por dispositivos formais visa somente não atrapalhar o seu corrente funcionamento, as relações de dominação e as hierarquizações estabelecidas em instituições como a escola parece apenas tornar intacta a ordem existente e corresponder a uma perspectiva disciplinar necessária, porém, anacrônica ao tempo presente. Isso significa que pouco essa rede tem sido vista nessa instituição como parte de uma comunidade mais ampla que dela se diferencia, ao apresentar um modo distinto de existência e ao ser guiada por uma outra norma - a vital ou da vida, nos termos em que Canghilhem (1997) a pensou. E, provavelmente, essa pouca visibilidade ocorre em virtude da aparente desorganização política formal dessa rede que, embora possa se organizar e o faça politicamente do mesmo modo que outros movimentos sociais, mantém certa forma de auto-organização espontânea, inconsciente, paralela ou transversas aos jogos de poder institucionalizados. Já que não se pauta numa consciência plena do fazer empreendido pelos movimentos sociais organizados, se usarmos a designação que lhe confere Fernand Deligny (2015), essa rede se entretece por certa inconsciência, ao mobilizar forças distintas e sentimentos comuns para uma ação que se inerva e se irradia numa comunidade mais ampla, ao aglutinar deficientes, seus pais e cuidadores sem um plano aparente. Com a imprevisibilidade das circunstâncias, a mobilidade dos sentimentos e a 
expressividade de suas imagens, essa rede é estratificada, dando base às relações interpessoais que nela se entretecem e propiciando uma amizade capaz de se expandir da esfera privada, em que nascem, para a esfera pública, em que configuram seus modos comuns de existência. Contudo, a emergência desses modos comuns de existência na cena pública, por vezes, também se distingue daqueles em vigor e dos estratos sociais hegemônicos. Por isso, com alguma frequência, essas relações interpessoais e de amizade podem afrontar a moralidade dominante e as políticas de inclusão excludentes, em função, sobretudo, da eticidade e da reflexividade que produzem nos partícipes da rede e, muitas vezes, dos afetos que provocam com a sua emergência na esfera pública. Concomitantemente aos eventuais consensos sociais, a aparição dessa rede indica uma convivência com os modos de existências que expressam às comunidades que se embatem na esfera pública e provoca esta última a se defrontar com a diferença radical que seus partícipes representam ${ }^{6}$, colocando aí em jogo essas vidas que merecem ser vividas e que se diferenciam eticamente, como quaisquer outras, das demais.

No que concerne à escola, essa rede a atravessa na medida em que aí se apresentam informal, casual e espontaneamente, de modo a ultrapassar os dispositivos tecnológicos, a preocupação dos professores com programas de conteúdos curriculares, métodos de ensino e avaliações adaptadas, a ocupação dos especialistas com serviços de acompanhamento especial, dentre outros de fundamental importância. Isso porque essa rede é mobilizada por encontros que ocorrem aleatoriamente entre os atores dessa instituição, independentemente de

\footnotetext{
${ }^{6}$ Procurei falar dessa rede invisível em outras ocasiões (PAGNI, 2015a; 2015b) sem usar a referência a Deligny (2016). Em linhas gerais, ofereci alguns exemplos de relatos para mostrar como essa rede se entretece por uma espécie de sentimento (do) sublime em torno do qual essa espécie de animalidade movida por organizamos vivos deficientes ou que mobiliza aqueles que deles se aproximam em função dos cuidados dispensados e dos afetos decorrentes dessa experiência singular em que testemunha sua transformação e colocam em movimento suas vidas. Diferentemente, nesta ocasião me concentro em situar como essas relações intersubjetivas com os deficientes ocorrem, não propriamente no contexto familiar ou na vida ordinária, mas, particularmente, na escola, a partir do que entendo por uma espécie de amizade com esse ser deficiente e da ética que daí decorre. Assim, compreendo que a ética da amizade alimentada por essa rede, por sua vez, também proporciona uma formação ética dos atores dessa instituição que contrasta com sua função moralizadora, assim como, uma vez eliminada a distinção entre atores e coadjuvantes, convida a uma relação aberta com a diferença como meio para que o convívio com as próprias deficiências possa ser enfrentado como uma espécie de programa, nos termos anteriormente assinalados.
} 
serem ou não designados deficientes. É assim que essa rede se entretece, alimentada por afetos e experiências mais do que por trocas racionais e linguísticas, constituindo relações intersubjetivas que contrastam, algumas vezes afrontando, outras vezes confluindo às exigências formais, objetivas e instituídas nessa instituição, seus dispositivos tecnológicos, sua regulamentação jurídica e sua norma moral. E, por sua vez, são em relações intersubjetivas como essas que a amizade emerge e, no caso em que se dá entre atores que possuem modos de vidas determinado por alguma deficiência, ela se apoia numa dissimetria e na sorte de um vínculo entre diferentes para o qual a necessidade da confiança se apresenta como uma condição e como um meio para a consecução de uma ética própria.

Para essa ética, a amizade com a deficiência, distintamente da identificação com outrem em função das semelhanças projetadas por um dos atores ou das expectativas de cuidado esperado pelo outro, supõe uma diferenciação entre eles: um estranhamento provocado muitas vezes pela dessimetria de suas capacidades intelectuais, de sua força física ou pelas suas debilidades e deformações provocadas por acidentes aos quais esse outro foi submetido e com os quais aprendeu a conviver. Nesse sentido, este outro, designado de deficiente, seria também um ser especial, pois, de acordo com Giorgio Agamben, além de insubstancial, o ser especial "não tem lugar próprio, mas acontece a um sujeito, e está nele como um habitus ou modo de ser" (2007, p. 46). Nesses termos, o deficiente não seria especial por ser carente de cuidados ou cuja diferença mobilizaria certo sentimento de compaixão ou produziria a piedade em relação a esse outro apenas com o objetivo de afirmar-se e de mostrar-se virtuoso de acordo com a moral existente, tal como ele é tratado ordinariamente.

Muitas vezes, em seu sentido ordinário, esse modo de ser é visto a partir de suas qualidades ou - poderia acrescer - defeitos, que caracterizam sua diferenciação dos demais e substancializando-o como tal, como diferente. Isso ocorre na medida em que esse modo de ser se identifica a uma imagem que expõe acerca de si mesmo e que supostamente o identifica com aquilo que é e a um agrupamento de pessoas, classificadas conforme um gênero preestabelecido e 
prescrito por uma categoria universal. O problema dessa compreensão ordinária, segundo a interpretação do filósofo italiano, é o de que ela ignora que o ser especial comunica a outrem, por intermédio da exposição de sua imagem, não somente o que é, suas qualidades particulares, como também um desejo de se imaginar como algo ou alguém que não corresponde ao ser efetivo. Parece ocorrer aí, algo análogo à projeção em um espelho que faz com que nos arrumemos para um olhar alheio, mesmo intuindo que aquela imagem projetada já não revele integralmente o que somos. Nesse caso, haveria certa defasagem, um hiato ou, mais precisamente, um intervalo entre a imagem projetada e o modo de existência do ser que a projeta, que seria impelido por esse desejo de ver naquela imagem uma representação mais desejável, para que possa ser amada por si mesmo, ao mesmo tempo em que esse amor a si seria percebido por outrem Isso porque esse outrem vê aí, contudo, tanto a imagem que se apresenta e perfaz quanto esse intervalo entre uma imagem projetada e o que é esse ser especial que se apresenta, reconhecendo nele algo comum a si, a saber, uma intenção (intentio), isto é, uma tensão interna (intus tensio) responsável por impelir o ser para fora, se comunicar e se expressar. Afinal, diz Agamben:

A espécie não é, nesse sentido, nada mais que a tensão, que o amor com que cada ser deseja a si mesmo, deseja perseverar no próprio ser, comunicar a si mesmo. Na imagem, ser e desejar, existência e esforço coincidem perfeitamente. Amar outro ser significa: desejar a sua espécie, ou seja, o desejo com que ele deseja perseverar no seu ser. $O$ ser especial é, nesse sentido, o ser comum ou genérico, e isso é algo como a imagem ou o rosto da humanidade. (2007, p.48 - grifos meus).

Embora alguns valores e certa cultura nos induza a vê-los dessa forma, o ser especial $^{7}$ da perspectiva proposta seria como qualquer um e, portanto, pertenceria a

\footnotetext{
${ }^{7}$ Com essa definição emprestada de Giorgio Agamben (2007), a espécie se caracterizaria, ao invés da subdivisão do gênero, a sua exposição, sendo que o ser, desejando e sendo desejado, nela se torna especial na medida em que se torna visível. E, nesse caso, dá visibilidade àquilo que não pode ser identificado como esta ou aquela qualidade que lhe é peculiar - tampouco por seu defeito ou deficiência, é possível acrescer -, mas por se apresentar como "qualquer um, a saber, um ser tal que é indiferente e genericamente cada uma de suas qualidades, que adere a elas sem deixar que nenhuma delas o identifique" (AGAMBEN, 2007, p. 47). Por isso, a diferença expressa ou comunicada pelo ser especial parece se apresentar como similar a um rosto, a um gesto ou a um acontecimento que, ao não se assemelhar a nenhum, "se assemelha a todos os outros" e se oferece a um uso comum que não pode se reduzir a um "objeto de propriedade pessoal". Nessa direção, para Agamben (2007, p. 47), o ser especial "comunica apenas a própria comunicabilidade", que é inseparável do genérico e da possibilidade do amor, ainda que as formas usuais de comunicação e os usos que aí se faz da
} 
uma espécie mais ampla, a saber, a nossa espécie. Ao assim concebê-lo, a sua particularidade e singularidade se responsabilizam por ampliar as margens do que é comum a nós para além da curva mediana da normalidade e nos auxilia a abrir espaço para o convívio com modos de existência distintos dos nossos, que povoam a comunidade de outros modos de existir sustentados em regimes de verdade diversos, nem sempre evidenciados pela maioria tampouco estabelecidos como "normais". O especial se refere ao que esse ser mostra de comum a outrem e, ainda que este não queira reconhece-lo como tal, força-o a vê-lo como próximo ou, por assim dizer, familiar a si mesmo.

Graças ao fato de não ofuscar o hiato existente entre a sua imagem e aquilo que é, tampouco de apagar o amor ou o desejo que procura preenche-lo para se perpetuar e afirmar a sua vida singular, esse modo de converter a visão ou essa força se apresenta como uma espécie de devir imanente a esse ser e, caso se queira, que se torna perceptível em sua ação. Ainda que essa ação produza de imediato um estranhamento suscitado nesse encontro propiciado pelas relações intersubjetivas, ele não é apreensível plenamente pela lógica identificante, pelos dispositivos classificatórios das categorias fixas e pela linguagem ostensiva utilizadas pelos seres que nela se relacionam e se comunicam. Nessa relação ou comunicação, o que torna esse estranhamento familiar é o seu devir percebido por outrem na medida em que esse ser o expõe e o força a percebê-lo como próximo e comum também a si mesmo. Dessa forma, o ser especial sugere o que possui em comum com a humanidade, mostrando em seu rosto certa tensão interna imanente à vida, que, uma vez posta para fora, revela um intervalo entre o que somos e a imagem que projetamos, assim como o amor que o conduz a ser de outro modo, graças ao seu devir, denominado aqui deficiente ${ }^{8}$.

linguagem tente subtrair seus modos de ser a uma imagem e a um "eu" coerente e idêntico para transformá-lo num espetáculo de diferenciação, às custas de sua separação da espécie, da perda da possiblidade da circulação do amor nesse registro comunicacional e, poderia acrescentar, da emergência amizade nesse aspecto da relação intersubjetiva que constitui o contexto interlocutório.

${ }^{8}$ Assim o denomino, particularmente, porque tal movimento decorre da distorção percebida entre a imagem e o que somos nós e da mobilização do desejo para que nos tornemos idênticos a ela no sentido de que nos sirva como um guia para que ultrapassemos as nossas fraquezas, errâncias, deficiências, e busquemos uma autosuperação do que reconhecemos como nossos déficits. Nem sempre, porém, essa atitude reativa à percepção de nossos déficits logra êxito, fazendo-nos obrigados a que as forças que impedem a superação das 
Nisto consiste um devir deficiente que, como uma variação do modo como o concebeu Agamben (2007), se apresenta ontologicamente como um rosto, um acontecimento e um gesto capazes de designar o comum nas relações de seres singulares com a espécie, sobretudo, quando tais seres corporificam uma marca da humanidade em que esta persiste em não ver. O comum existente nesse ser especial não é a meu juízo da ordem do reconhecimento racional, tampouco do imperativo moral de que uma vez percebido os déficits devamos automaticamente superá-los, mas da ordem da percepção sensível e do trabalho ético que implica, além do desejo do sujeito, o exercício do pensar em relação ao poder ao qual seus órgãos vitais e seu corpo estão submetidos de alguma forma, assim como a potencialidade e a possível gestão da força vital aí catalisada.

É esse pensar que assume uma configuração própria, porém, atinente também à espécie e, portanto, a uma das faces da humanidade, tal como anteriormente mencionada. Nesse caso, a corporificação do devir deficiente como modo de ser - que é responsável pelo sujeito receber essa designação social de "deficiente" -, consiste numa singularidade ou especialidade que evoca uma série de traços, de sentimentos e de imagens comuns. Alguns desses traços físicos ou psíquicos são julgados socialmente, em sua condição ordinária, como negativos a um ideal de vida sã e à sua performatividade no mundo ou, mesmo, notados como indesejáveis. Isso porque eles evidenciam sob essa ótica os limites, deformações e disfunções decorrentes dos acidentes sofridos (genéticos, físicos, neuronais, etc.) por esse sujeito, despertando sentimentos diversos como repugnância, pena ou, mesmo, medo. Talvez, essa seja a sua face mais inumana, para usar precisamente uma expressão de Jean François Lyotard (1998), que, potencialmente, os chamados "deficientes" invocam e que poderia ser voltada contra a desumanidade e a inumanidade do próprio sistema biopolítico atual. Em outras palavras, isso significa confrontar o próprio estigma do que os deficientes representam socialmente, a repugnância e o temor que suscitam psiquicamente por sua presença tão estranha e, ao mesmo tempo, tão próxima, como exposto, por poder de governa-las e, particularmente, de superá-las. 
meio da invocação de um trabalho ético acerca de si mesmo, do ato de pensar daí decorrente para vislumbrar o que há em comum com essa face inumana de uma humanidade que, antes do que reconhecida como nossa, também circula em cada corpo, se entretece no tecido e se aglutina no corpo social.

É por esse caminho que julgo também ser possível evocar esse ato de pensar, em vistas a dar visibilidade e a facultar aquele trabalho ético na escola, como uma prática estrategicamente importante todas as vezes que essas representações aparecem tanto em seus dispositivos formais quanto nas redes que a atravessam informalmente. Esse trabalho pode emergir, afinal, na medida em que repercutem nos corpos dos atores da escola, se entretecem na forma das amizades que são transversais a essa instituição e se configuram como uma ética que faculta a ocorrência da diferenciação de si mesmos. Analogamente ao que escreveu Michel Foucault acerca da amizade entre adultos do mesmo sexo, considero que tais amizades provocam um curto circuito na lógica interna da escola e na cultura que faz circular na atual racionalidade da biopolítica que a permeia enquanto instituição social. Como um contraponto às políticas de inclusão, a ética da amizade com os deficientes, parece indicar dessa forma uma eventual ruptura histórica ou, mesmo, um acontecimento pouco notado pelos atores dessa instituição, pelos campos de saber e como um fecundo terreno para sua reflexibilidade na filosofia da educação. Contudo, para que isso ocorresse seria imprescindível que se pensasse no combate a desconfiança em relação à potencialidade desses modos de existência que exprimem os deficientes e ao devir comum que evocam, antes mesmo de discutir a confiança como a condição da ética da amizade com os deficientes e como um caminho de sua propagação no âmbito transversal da escola.

Combater a desconfiança, confiar no devir deficiente: uma condição ética da amizade

A amizade se pronuncia por meio de uma linguagem marcada pela intensidade dos instantes e pela rejeição absoluta à proliferação de adjetivos que interpelam, acusam, difamam. Como se se tratasse de uma linguagem limpa, fruto de um 
olhar limpo numa duração sem fundo, que impede a passagem de todo julgamento e que abre as portas para uma hospitalidade sideral, sem impor condições. (SKLIAR, 2014, p. 50)

Desconfia-se, particularmente, do que se refere à proficuidade do sucesso dos deficientes como capital humano, nos termos em que apresentei brevemente ao retratar a situação da política de inclusão no Brasil e, mais superficialmente, a sua articulação com a biopolítica neoliberal. Nesse cenário, tudo que é estranho, distinto e que difere eticamente de si parece ser objeto não apenas de desconfiança, como também de ódio para o sujeito, despertando uma reação fascista que parece decorrer da frieza dessa racionalidade e, particularmente, do empobrecimento das relações intersubjetivas que abarcam o tecido social. Se, por um lado, essas reações diante do deficiente emergem e deixam à mostra uma desumanidade ou uma inumanidade do próprio sistema econômico - e não somente para os "deficientes" -, por outro, elas indicam que em tais sujeitos há uma vida vivida, incontrolável, excessiva e expressa pelo segmento da população assim denominado. Muitos reconhecem socialmente nessa figura denominada "deficiente" uma afronta de alguma forma tanto ao tecido social empobrecido quanto à racionalidade econômica empreendida no cenário biopolítico atual e, particularmente, a sua distribuição na escola. Nesse contexto particular, tornar visível as relações de amizade com a deficiência pode ser, estrategicamente, um modo de promover o tão propagado curto-circuito na lógica empreendida por esta instituição e, senão tornar mais rico, ao menos propiciar um tecido social mais entretecido por redes que evitem modos de existências fascistas e, principalmente, as suas práticas, quais seja, aquelas que mobilizam o temor e, especialmente, propagam o ódio contra essa ou qualquer outra diferença.

$\mathrm{Na}$ conjuntura atual, a desconfiança parece ser gerada justamente pelo temor, pelo desconforto ou pelo incomodo de que essa potência deficiente, por assim dizer, poderia se converter em ato e transformar os modos de existência, produzindo uma intensidade da vida e um movimento num lugar em que somente existiria o seu controle técnico-racional e uma suposta sensação de segurança gerada pela fixidez, pela identidade e pela normalização dos demais sujeitos. Tanto reconhecer esse outro como rosto da humanidade quanto o devir 
deficiente comum em relação a si mesmo seria admitir uma vitalidade e uma mobilidade perturbadoras de certa formalização das categorias do entendimento, da determinação dos juízos e da harmonização das faculdades. Isto implicaria, também, em buscar outras formas de pensar, de julgar, de sentir e de exprimir que interpelariam a identidade dos sujeitos, a sua segurança e a conformidade de suas ações à racionalidade econômica e aos princípios de eficiência consonantes com a biopolítica neoliberal ou, guardada as devidas proporções, com o que Maurizio Lazzarato (2014) denominou de "servidão maquínica" ${ }^{9}$. Do ponto de vista desse intelectual italiano, para que essa cena de interpelação possa ser vislumbrada seria preciso que ela provocasse os sujeitos a romperem com a lógica do endividamento e, com isso, gerassem uma interrupção no atual círculo da crédito-dívida. Nessa lógica e nos processos de subjetivação que esse círculo produz, segundo Lazzarato (2013), haveria a exploração da ação ética responsável pela constituição simultânea da comunidade e do indivíduo, particularmente, das forças presentes em sua genealogia, dentre as quais se destaca a confiança. Isso porque as escolhas e as possibilidade éticas não estariam condicionadas somente do entendimento, da cognição, do saber e do conhecimento, como também a forças mais íntimas, marcadas pelo pathós e que poderiam ser resumidas no conceito de desejo. Lazzarato justifica essa genealogia das escolhas na medida em que considera a relação do êxito de qualquer ação no mundo com a energia despendida pelo ato e, portanto, compreendendo este último como condicionado à "certeza íntima", a uma “crença" em poder efetuá-lo ou a uma "crença-confiança” em realiza-lo (2013,

\footnotetext{
${ }^{9}$ Inspirado em Michel Foucault e Félix Guattari, Maurício Lazzarato (2014) afirma haver dois tipos de subordinação aos dispositivos do biopoder e a configuração da biopolítica neoliberal no presente. A primeira compreende os tipos de assujeitamento social que fazem com que forma cada sujeito, em conformidade aos papeis e às funções socialmente designadas, se constitua por uma semiologia a qual ainda tem algum poder de decisão e deliberação, ainda que restrito. A segunda diz respeito a uma espécie de formação das disposições e atitudes dos sujeitos sobre a qual intervém toda uma semiologia (significante e, principalmente, a-significante) na medida em que se subordinam às imagens da mídia televisiva e eletrônica, aos modos de existir que preconizam, instaurando a aquisição de hábitos, muitas vezes naturalizados conscientemente, mas que os aproximam a máquinas que reagem segundo os fluxos de capital e que os enredam numa dinâmica de endividamento sobre a qual a culpa de escapar desse registro maquínico e romper com essa lógica é o principal dispositivo. O primeiro tipo se refere a um tipo de controle da vida, por assim dizer, necessário para os modos de existência social, embora requeira uma hierarquização nem sempre compatível com as diferentes formas de vida que aí existem; enquanto que o segundo está relacionada a sua extrapolação na medida em que inviabiliza o próprio aprimoramento da vida coletiva, em razão da reiteração de um individualismo estéril.
} 
p. 74). O ato dependeria nesse caso da intensidade da "crença-confiança" e esta, por sua vez, da mobilização das forças mais íntimas para agir, que extrapolam qualquer modulação exclusivamente racional, apelando ao desejo e fundamentalmente aos fluxos que o constituem na sua relação subjetiva e intersubjetiva no mundo.

Ao problematizar a confiança que se assimila ao hábito adquirido numa relação com o estabelecido e com o existente, Lazzarato (2013) ainda indica uma condição mais profícua para o seu sentido associado ao fiar em si e nos outros, não como uma fé cega, mas como uma espécie de crédito obtido pela sua ação no mundo.

Esse crédito seria distinto daquele decorrente do investimento num capital humano que se apresentaria com maior risco para obter lucro, como sugerido por Foucault (2008), ou, no que se investe para endividar ao sujeito investido de modo a responsabilizá-lo pela gestão de si mesmo e pelo seu sucesso como uma empresa, nos termos apontados por Lazzarato (2013; 2014). Afinal, ela estaria relacionada a um ter fé em si, em alguém ou no mundo, independente do que se espera restituir como ganho pessoal ou como resultado destinado a ampliação de suas propriedades ou de seu capital financeiro. Nesse sentido, é um acreditar que rompe com a figura dos investimentos no capital humano empreendidos pela educação no âmbito da biopolítica neoliberal, já que o investimento de que se fala neste caso é no que ainda pode surpreender, no desconhecido, no que não se espera um retorno, e sim perdas (de tempo, de ganhos, etc.). Esse crédito rompe também com a figura do endividamento, porque escapa ao cálculo financeiro na medida em que assume a gestão de afetos e de uma aposta num outro de si cujo retorno não seria imediato nem visaria o lucro, mas sim a intensificação da vida. Por isso, é esse crédito obtido em razão da ação do chamado "deficiente" junto aos demais que valorizarei aqui com o intuído de oferecer uma outra direção às discussões sobre o seu sentido ético e o seu significado político no presente, quem sabe, um outro olhar sobre a desconfiança e, principalmente, um 
redimensionamento da confiança como condição e um dos meios da consecução dessa particular ética da amizade.

Nesse caso, o crédito é obtido pela aposta no caráter errante e aventureiro da experiência com o deficiente, que inverte a lógica atual de que quem está nela de peito aberto deve se sentir culpado, endividado para se programar e se assegurar, sem pôr em risco a própria vida: sempre a postergando para sobreviver, sobrevivendo para não viver, quase admitindo, que a própria vida não merece ser vivida. Assim, o crédito se destina a alguém que, advertidamente ou não, se joga e se põe em risco ${ }^{10}$, se destinando a quem assume eticamente o caráter errante de sua vida e se aventura numa ação em que o confiar em si, no mundo e nos outros não pode estar ausente. Justamente por isso, segundo Lazzarato, é necessário estabelecer um acordo tácito consigo, com o mundo e com os outros para agir fora das "máximas das rotinas" e do círculo crédito-dívida, pois, agir é "um salto ao desconhecido" (2013, p. 75) em que o conhecimento não auxiliaria a nos salvar de nossos atoleiros políticos, porque seriam de teor muito mais ético que cognitivo. Nesse registro, a confiança seria um "poder generoso" que pode fazer com que, ao crermos no mundo, encontremos aí novas e surpreendentes fluxos de vida, capazes de mobilizar nossas forças vitais para dar-lhes fluidez, desde que nos fiemos nas nossas disposições, energias e potencialidades para e na confluência da dos outros para converte-las em ato. Nessa direção, Lazzarato argumenta que "a confiança é a condição de todo ato de criação, trate-se de criação artística, ética ou política" e o homem contemporâneo deve sentir-se à vontade nesse "mundo bárbaro" para agir, já que exerce suas ações senão sobre "fatos brutos" (2013, p.79), ao menos sobre possibilidades que implicam suas escolhas e opções.

Como ato de criação, a meu ver os modos de ser deficientes e o seu devir comum atuam no mundo no sentido de afrontar o mundo bárbaro por algo que advêm de um estado corpóreo e de uma vida infame que muito se aproximam de

\footnotetext{
${ }^{10}$ Nesses termos, Foucault (2009) a concebeu em seu último curso ao alinhavar a parresia cínica e a sua coragem de verdade com a revolução como modo de existência e, posteriormente, Maurizio Lazzarato (2014) a retomou para mostrar as diferenças de sua posição em relação aos projetos de democracia de Alain Badiou e Jacques Rancièrè.
} 
uma barbárie e de uma inumanidade próxima à da produção artística ou, ao menos, de uma vida como obra de arte. Dessa perspectiva, pode-se dizer que a confiança e o desejo desenvolvem-se num "presente vivo", para usar outra expressão de Lazzarato (2013, p. 79), isto é, numa “zona plástica” em que as diferenças individuais e as mudanças sociais por elas provocadas indicam novas possibilidades e, ao mesmo tempo, exigem uma posição dos sujeitos em relação a si mesmos. Seria necessário para tanto pressupor a confiança para esperar aquilo que ainda não chegou e que pode tornar possível o impossível.

Diferentemente do medo, dos afetos e das paixões tristes produzidas pela administração vital atual pelo círculo crédito-dívida no qual se assenta a biopolítica neoliberal, a confiança do que pode advir daquela "zona plástica" e a esperança nestas suas possibilidades "determinam não tanto uma tomada de posição, uma decisão acerca das crenças vigentes, senão uma auto avaliação de novas crenças, valores, modos de vida" capazes de potencializar a ação no mundo e, com isso, promover a afirmação da existência (2013, p. 81). Nessas possibilidades parecem se vislumbrar a confiança como uma criação de modos de existência e esta, por sua vez, como condição de possibilidade da amizade com as formas de vida deficientes, assim como a esperança num devir comum que produz nas relações entretecidas com os demais sujeitos. Ao devir deficiente percebido nas relações intersubjetivas, pode-se creditar não somente uma eventual transvaloração dos valores existentes, como também modos de existência éticos singulares e suas formas de organização comunitária, em rede, como capazes de resistir ao círculo econômico ao qual estamos todos enredados e quanto aos dispositivos do biopoder instituídos. Assim sendo, é possível vislumbrar um outro olhar sobre os deficientes e confiar no devir que eventualmente produzem na relação com os demais, graças aos efeitos interpeladores que proporcionam, assim como no que mobilizam em relação ao comum e a si mesmos.

Para que isso ocorra, porém, é necessário que os sujeitos com quem os deficientes se relacionam sejam convencidos a confiar neles e, porque não dizer, forçados a dar crédito ao devir comum que produzem nessa relação e que também 
pode ser, senão reconhecidos, ao menos percebido em si mesmos. Judith Butler afirma que "a capacidade do sujeito interpelado tanto para a autorreflexão quanto para o reconhecimento social, (...) são essenciais para qualquer relato substantivo da vida ética" (2014, p. 68-69). Acrescentaria a tal afirmação da autora que essa vida ética, em consonância com que expusemos anteriormente, pode aludir ao comum ao qual a sua expressividade ou narrativa se destinam e, com ele, entretecer redes em torno de modos de existência outros, criados a partir da interpelação que aquela expressividade e essa comunidade provocam, respectivamente, em outrem e na vida pública. A meu juízo isso ocorreria na medida em que, ao se apresentarem nas relações intersubjetivas e comunicacionais, os deficientes e o que eventualmente produzem como comum, conseguissem mobilizar em alguns de seus interlocutores, em razão do estranhamento que suscitam imediatamente, um pensar crítico, um julgamento reflexivo, um sentimento (do) sublime e algumas dificuldades linguísticas em expressá-los.

Eles deslocariam dessa forma os demais sujeitos de seus estados de pensamento, julgamento, sentimento e linguagem que se encontram, interpelando o que se pode denominar de suas identidades. Chegam, por vezes, ao ponto de exigirem dos sujeitos interpelados com os quais se relacionam e se comunicam, sem dizerem muitas vezes nada e se apresentarem somente como um signo à percepção alheia, se dobrem sobre suas vidas e seus afetos para compreendê-los e, quiçá, demandarem outros jogos de linguagem quando os significados e a linguagem ostensiva em circulação não permitem mostrar o que têm em comum com esse outro e o devir que o vinculam a si mesmos. Sob esta ótica os chamados os deficientes poderiam ser vistos positivamente e, até mesmo, o devir que produzem em suas relações intersubjetivas poderia ser considerado desejável. Isso porque em suas ações e em seus modos de existência podem ser notados o esforço, a vontade e o desejo dos deficientes em superarem a sua imagem negativa (advertidamente ou não), em contornarem os sentimentos desconfortáveis que suscitam e em vencerem a desconfiança que despertam socialmente. No limite, 
ainda, é possível dizer que eles se afirmariam como capazes de descolocar certo julgamento desfavorável e lutar por um lugar nesse mundo, seja para reiterar a sua ordem e hierarquização prévias, seja para afrontá-las e, quem sabe, resistirlhes em vistas à sua transformação. Constituir-se-iam nessa direção, para usar uma expressão de Martha Nussbaum $(2007 ; 2010)$, como uma das novas figuras do reconhecimento e da "justiça social".

Com a emergência dessa nova figura talvez seja possível vislumbrar nas relações intersubjetivas com os deficientes e no devir comum que eventualmente produzem não apenas uma valoração positiva, como fazem todas as ontologias que tentam ajustá-los pelo fato de terem um rosto humanizado, como também, ao menos para aqueles que consideram desejáveis certa abertura e vivem a vida como diferença, um lugar como o de qualquer outro e um móvel capaz de intensificar os sentimentos, fazendo emergir dessa intensificação a criação de signos e, sobretudo, de existências outros. É com aquele distinto modo de se relacionar com esse outro, como qualquer um e com essa intensificação de vida utilizada como critério (erótico) para subjetivações outras, que os modos de existir deficientes poderiam emergir e serem vistos nas relações intersubjetivas, nutridos por uma ética da amizade entre diferentes, porém, não em princípio entre desiguais. A igualdade presumida nessa amizade pode se dar por uma condição de igualdade do deficiente em relação aos demais, não garantida pela semelhança das suas capacidades físicas e intelectuais ou por algum estatuto jurídico ou, mesmo, dos mesmos sentimentos e crenças defendidas por eles, mas por uma forma de dignidade expressa no testemunho de uma vida que merece ser vivida. Essa vida retrata seus distintos modos de existência e implica em uma performatividade no mundo para que sejam acolhidos como qualquer outra e em que o rosto da humanidade se apresenta, mesmo em sua inumanidade.

Por esse motivo a amizade presumida nessa relação intersubjetiva com a deficiência pode ser em princípio assimétrica, mas a experiência comum que produz insta a diluir essa assimetria e, mais do que aprazível, torna desejável o convívio com modos de existir diversos. Algo que acontece, sobretudo, quando 
alguns sujeitos sentem-se interpelados pela presença dos chamados deficientes e estes, por sua vez, ao experienciarem seu devir e o exprimirem como parte dessas formas singulares de existência, fazem com que a vida aí pulsante em seus corpos persista e persevere, não se dobrando plenamente as expectativas, as normas e as regulamentações instituídas. Ao contrário, eles parecem resistir aos seus dispositivos funcionais, criando possibilidades para que o mundo que habitam seja revisto por outro programa mais aberto e capaz de acolher as suas diferenças, seguindo o projeto da ética foucaultiana da amizade e a sua relação com a deficiência, anteriormente esboçados.

Para que essa sensibilidade à diferença e aquele programa se produzam em instituições como a escola, todavia, é necessário confiar no devir deficiente como uma condição para que a ética da amizade com os atores que o corporificam se apresentem como signo de uma experiência com um acontecimento singular desconhecido e, particularmente, que necessitaria ser desvendada, reconhecendo aí a emergência de uma nova ética - antes do que somente uma nova figura do reconhecimento. Assim, ao serem por elas interpelados, os demais sujeitos que não tem incorporado esse devir poderiam vislumbrá-lo em sua potencialidade produtiva de modos de existência outros para si mesmos, para ampliar os espaços de seu acolhimento de suas diferenças nas relações intersubjetivas do tecido social e para auxiliar a recriar outras formas de organização no mundo, capazes de propiciar a perseverança em uma vida comum, mesmo diferente.

A confiança seria dessa forma uma condição para a amizade com a deficiência e estaria implicada desse ponto de vista com uma percepção aguda dessa diferença radical e com os seus efeitos para o devir dos próprios atores interpelados por ela. E, particularmente, interpela o que se refere ao modo como esses atores se relacionam com seus próprios déficits, com as tecnologias utilizadas para saná-los, superá-los ou contorna-los, encontrando aí um devir comum ao rosto da humanidade que se lhe apresenta, mas raramente é visto, ainda que seja persistentemente mostrado. Por sua vez, a surpresa decorrente desses efeitos conscientes nos atores com quem eventualmente se tornam amigos, 
também, faz com estes últimos percebam e creditem aos deficientes uma fé de que jamais deixariam de lhes ser leal ou de lhes fazer qualquer maldade, justamente porque agiriam fora da lógica da troca de equivalentes em que a amizade se constituiu preponderantemente no presente e de sua formulação utilitarista. Embora nem sempre essa expectativa se efetue nas amizades com os deficientes já que como um qualquer também estariam subjugadas a uma racionalidade econômica -, esses atores buscam encontrar um acontecimento que os faça esperar que uma comunidade outra advenha, um respiro para recobrar a intensidade ética da vida e reformar a densidade do tecido social, respectivamente, agenciados e empobrecidos no presente. No signo dessa esperança ou do eventual entusiasmo ${ }^{11}$ despertado por esse encontro com um acontecimento como este parece nascer essa confiança nos deficientes, que ultrapassa o seu registro meramente consciente na apreensão do devir comum que suscitam e, mesmo, na sua simples comunicação a outrem por meio de uma linguagem ostensiva ou de gêneros que circundem em torno de qualquer cognocentrismo. Resguardado essa circunscrição, parece ser possível compreender a confiança não apenas como condição, como também como algo que ocorre em meio a uma comunicação- sem comunicação, talvez, como sugere Lyotard (1998) - ou de uma pragmática particular concernente à ética da amizade com os deficientes.

\section{Considerações finais}

[...] a amizade tem um valor incontável, incalculável: não se conta, não há quantidades, jamais existem somas, jamais se resta.

É por isso que a voz provém e devém de inúmeras vozes. Já não se importa de quem, já não se importa como, já não interessa quando: estranha sensação de uma companhia incondicional que, mesmo ausente, calada no maior dos silêncios, parece permanecer em todos os lados. (SKLIAR, 2014, p. 51).

Este ensaio circunscreve a esse ponto, acompanhados também pelas epígrafes extraídas do aforismo Linguagem da amizade de Carlos Skliar, o lugar incerto de propulsão de um curto-circuito produzido pela presença dos modos de existência deficientes e de seu devir comum na escola. Por esse viés, procurei

\footnotetext{
${ }^{11}$ Inspiro-me aqui no modo como como Lyotard (1997) analisa o entusiasmo como efeito dos pequenos acontecimentos decorrentes da revolução francesa.
} 
colocar em xeque não apenas as políticas de inclusão, particularmente, o que elas dizem estar atentas em relação à especialidade da deficiência, como também boa parte dos dispositivos da instituição escolar, em vistas a colaborar para ampliar a visibilidade dos modos de ser deficientes aí presentes.

As primeiras foram interpeladas por essa ética da vida comum, pois, as políticas de inclusão, nos termos analisados, buscam na especificidade da deficiência e no trabalho com os deficientes uma forma de enquadramento para seu melhor acompanhamento no tempo, no espaço, no currículo escolar. Raramente, os atores dessa instituição veem que paralelamente a eles, e ao instituído, ocorre uma relação interpessoal entre o deficiente e os demais alunos, ao ponto de termos alguns relatos que testemunham uma amizade para além da escola. Afinal, professores, diretores, coordenadores e demais atores dessa instituição pouca atenção dão atenção a esses relatos, às formas de sociabilidade e de amizade que emergem entre os estudantes, assim como o que delas se pensa, contribuindo tanto para os deficientes quanto para os demais. E a meu juízo esse seria um dos campos para investigar como as práticas de inclusão construídas desse modo mais espontâneo e por uma ética da amizade com a deficiência intervêm no ambiente escolar por formas de ampliação e de resistência às políticas púbicas de inclusão em curso, quem sabe com isso, produzir um outro olhar sobre a temática.

Por sua vez, se verifico também neste ensaio que pouca percepção se tem tido acerca dos acontecimentos decorrentes da presença do deficiente na escola que, em função das exigências garantidas judicialmente por tais políticas, além de formas de sociabilidade e éticas de amizade contrastantes com as instituídas, afrontam os sentidos homogeneizadores, padronizadores e normalizadores da escola. Se essas funções disciplinadoras e moralizadoras que configuram a escola desde a modernidade são interpeladas por essa espécie de amizade com o/as deficientes entre seus atores e, particularmente, pela qualificação de um grupo dentre eles, a exposição de seus modos de existência nesse espaço e tempo, isto é, a sua simples presença, radicaliza essa problematização no que se converteu essa 
instituição no presente. Isso porque a sua presença contrasta e afronta a assunção de certo princípio de eficiência pelos processos de ensino e aprendizado na atualidade, do imperativo da autosuperação para alcançar o sucesso material a qualquer custo e da tese política de que seria preciso evitar toda deficiência para tornar inclusivo os sistemas educativos configuram a escola no tempo presente, ao menos no caso brasileiro.

Ao invés de evitar a deficiência de todos e programar a eficiência, parece ser estrategicamente importante mapear os déficits e as deformações causadas por acidentes não para superá-los, mas para acolhê-los na sua insuperabilidade e para potencializar a convivência com esses limites constitutivos de si mesmos. Nesse trabalho ético consigo mesmo, produzida na relação com a deficiência, os seus atores podem buscar uma linha de fuga não somente para compensar esses seus déficits ou para neutralizar os efeitos dos acidentes que lhes acometem, visando suas outras potencialidades, como também para fazer daquilo que é neles insuperável uma potência passiva, que configura o que são e suas formas de existir. Não se trata, com isso, por meio desse processo de subjetivação apaziguar as tensões constitutivas dessa relação consigo para se chegar a um ethos estável, guiado pela consciência e exprimível pela linguagem, mas de torna-las visíveis, expondo publicamente seus modos de existência em devir e partilhando com outrem as suas formas de expressividade possíveis. Justamente porque o que move tais processos de subjetivação mencionados independem parcialmente dessa consciência e dessa linguagem, eles podem encontrar brechas em relação ao que lhes subjuga, ao mobilizar forças e imagens responsáveis tanto pela criação de formas de vidas outros quanto pela sua potencialização e afirmação no mundo, distinguindo dos existentes e, consequentemente, se singularizando no que diz respeito ao modo como se apresentam no mundo.

Por seu turno, as formas singulares de existência mencionadas também encontram uma multiplicidade de estilos de existência no mundo em que atuam e nas relações interpessoais que o compreendem. Embora sejam distintas das suas, tais formas singulares partilham com algumas das experiências que as produziram 
e vislumbram horizontes comuns, em torno dos quais se aliam, numa estratégia ensaiada, que tem o auxílio do consciente e de certa racionalidade, mas não o protagonismo deles, nem um fim definitivo ou télos almejado em nome de universais. Nesses rearranjos, encontros e desencontros se buscam um comum em que as diferenças qualitativas poderiam ser vistas e aceitas, tendo o dissenso como seu motor primordial, restando acordos vitais em torno dos quais os lugares do jogo se alternam, em virtude do agonismo entre modos de vida que aspiram uma maior abertura na/da comunidade e, porque não dizer, maior liberdade.

Para essa comunidade em construção, a confiança se constitui em condição e meio de consecução de uma ética da amizade com a deficiência. Isso porque confiar em outrem é não apenas dividir responsabilidades, tarefas sociais ou funcionais, como exposto neste ensaio, mas é esperar que, na singularidade de sua existência e na diferença que foge a toda e qualquer representação, o não esperado advenha na relação e um gesto nela possa surpreender de modo a provocar um estranhamento tal capaz de os atores com ela envolvidos se dobrarem sobre si mesmos. No caso em apreço, a presença do deficiente poderia provocar em outrem, como argumentado neste ensaio, o dobrar-se sobre si mesmo e sua própria deficiência, esse parece ser o foco principal desse processo de subjetivação, qual seja, o do intransponível que ninguém parece vislumbrar, fazendo com que esse aspecto insuperável de sua existência seja acolhido como parte de si e transformado de ato em potência. Mas esse movimento só ocorre se, nessa relação, houver confiança entre os atores, como aqui demonstrado, não no sentido de que ambos se tornam transparentes uns aos outros no sentido de se darem a conhecer ou a reconhecer, mas no de que se mostram por uma imagem que muitas vezes destoa do que são e que se configura tanto para um quanto para outro, indicando o que deles difere e uma busca sem fim para se revelarem a si mesmos.

\section{Referências}

AGAMBEN, Giorgio. Profanações. São Paulo: Boitempo, 2007.

ARENDT, Hannah. A vida do espírito. 2. ed. Rio de Janeiro, Civilização Brasileira, 2010. 
BUTLER, Judith. Relatar a si mesmo: crítica da violência ética. Belo Horizonte: Autêntica, 2015.

CALDERÓN ALMENDROS, Ignacio. Educación y esperanza en las fronteras de la discapacidad: estudio de caso único sobre la construcción creativa de la identidad. Madrid: CERMI/Ediciones Cinca S.A., 2014.

CANGUILHEM, Georges. O normal e o patológico. 6.ed. Rio de Janeiro: Forense Universitária, 2009.

CASTEL, Robert. La gestión de los riesgos. Barcelona: Anagrama, 1999.

DELIGNY, Fernand. O Aracniano e outros textos. São Paulo: N-1 Edições, 2-15.

FOUCAULT, Michel. De l'amitié comme mode de vie [Entrevista de Michel Foucault a R. de Ceccaty, J. Danet e J. le Bitoux], Gai Pied, no. 25, abril de 1981, pp. 38-39.

FOUCAULT, Michel. A escrita de si. In: FOUCAULT, Michel. Ditos E Escritos: ética, sexualidade e política. Vol . 5. Rio de Janeiro: Forense Universitária, 2004a, pp. 144-162.

FOUCAULT, Michel. O triunfo social do prazer sexual: uma conversação com Michel Foucault. In: FOUCAULT, Michel. Ditos $\mathcal{E}$ Escritos: ética, sexualidade e política. V. 5. Rio de Janeiro: Forense Universitária, 2004b, pp. 119-125.

FOUCAULT, Michel. Nascimento da biopolitica. São Paulo: Martins Fontes, 2008.

FOUCAULT, Michel. Le courage de la vérité. Paríis : Hautes ÉtudesGallimard-Seuil, 2009.

GILBERT, Ana Cristina Boher. Véritice do impensável : um estudo das narrativas em Síndrome de Down. Rio de Janeiro : Editora Fiocruz, 2012.

HABERMAS, Jürgen. O Discurso Filosófico da Modernidade. Lisboa: Publicações Dom Quixote, 1990.

LAZZARATO, Maurizio. La fábrica del hombre endeudado: ensayos sobre la condición neoliberal. Buenos Aires : Amorortu, 2013.

LAZZARATO, Maurizio. Signos, Máquinas, subjetividades. São Paulo : N-1 edições, 2014.

LYOTARD, Jean-François. Le différend. Paris: Les Éditions de Minuit, 1983.

LYOTARD, Jean-François. Lições sobre a analítica do sublime. Campinas: Papirus, 1993.

LYOTARD, Jean-François. El entusiasmo: crítica kantiana de la historia. Barcelona: Gedisa Editorial, 1997.

LYOTARD, Jean-François. O inumano: considerações sobre o tempo. 2.ed. Lisboa: Editorial Estampa, 1998.

NUSSBAUM, Martha. Las fronteras de la justicia: consideraciones sobre la exclusión. Barcelona: Paidos editorial, 2007.

ORTEGA, Francisco. Amizade e estética da existência em Foucault. Rio de Janeiro: Graal, 1999.

PAGNI, Pedro A. Experiência estética, formação humana e arte de viver: desafios filosóficos à educação escolar. São Paulo: Edições Loyola, 2014a.

PAGNI, Pedro A. Pensar a ética da amizade na escola: a emergência da poética na educação e uma atualização da estética da existência. Revista Sul-Americana de Filosofia e Educação. Número 23: nov/2014b, p. 364-386. 
PAGNI, Pedro A. Diferença, subjetivação e educação: um olhar outro sobre a inclusão escolar. Pro-Posições. vol.26, no.1,Jan./ Apr. 2015a, p.

PAGNI, Pedro A. Encontros com a Deficiência: de Ensaios da Ficção a Testemunhos Sobre a sua Ética em uma Rede (in) Visível. Revista Diálogos e Perspectivas em Educação Especial, v. 2, p. 89-106, 2015b.

RANCIÉRÉ, Jacques. O desentendimento. São Paulo: Editora 34, 1996.

SKLIAR, Carlos. Pedagogia (improvável) da diferença: e se o outro não estivesse aí? Rio de Janeiro: DP\&A, 2003.

SKLIAR, Carlos. Desobedecer a linguagem: educar. Belo Horizonte: Autêntica 2014.

Recebido em: 30.05 .2016 Aceito em: 15.06.2016 